\title{
Etapas e volume de treinamento das ginastas brasileiras participantes de Jogos Olímpicos (1980-2004)
}

\author{
Training phases and volume of training for Brazilian female gymnasts in \\ Olympic Games (1980-2004)
}

\author{
L.M. Schiavon, R.R. Paes, A. Moreira, G.B.M. Maia
}

\begin{abstract}
Os resultados das atletas brasileiras da Ginástica Artística Feminina nos últimos 10 anos apresentaram uma expressiva evolução nas competições de nível internacional. $\mathrm{Na}$ busca de informações dessa evolução, o presente estudo teve o propósito de conhecer o processo de formação desportiva das ginastas brasileiras participantes de Jogos Olímpicos entre os anos de 1980 e 2004. Para isso foi desenvolvida uma pesquisa qualitativa utilizando-se o método de História Oral. Participaram do estudo dez ginastas brasileiras classificadas para os Jogos Olímpicos. Decorrente das informações foi possível identificar tópicos específicos de análise no contexto da preparação de muitos anos: estrutura e organização dos treinos das ginastas, tempo de duração da etapa de preparação preliminar, volume de treinamento diário nas diferentes etapas e tempo de alcance dos resultados superiores.

Palavras-chave: treinamento desportivo, ginástica artística, jogos olímpicos
\end{abstract}

ABSTRACT

Results from Brazilian female Artistic Gymnastics improved over the past 10 years at an international level of competition. This study aimed at describing career development process in sports through a qualitative research resorting to the Oral History method. Ten Brazilian gymnast players in Olympic Games from 1980 to 2004 participated in the study. The information they provided allowed for the identification of specific variables present in their long term preparation: structure and organization of their practice, duration of the preliminary preparation phases, volume of daily practice in different phases of training, and length of time for the achievement of better results.

Keywords: sports training, gymnastics, Olympic Games

Submetido: 21.02.2010 | Aceite: 18.11.2010

Laurita Marconi Schiavon. Docente do Departamento de Educação Física da Universidade Estadual Paulista/ Campus Rio Claro, Brasil

Roberto Rodrigues Paes. Docente da Faculdade de Educação Física da Universidade Estadual de Campinas, Brasil Alexandre Moreira. Docente da Escola de Educação Física e Esporte da Universidade de São Paulo, Brasil Gustavo Bastos Moreno Maia. Doutorando da Universidade Estadual de Campinas, Brasil

Endereço para correspondência: Laurita Marconi Schiavon, Rua Fernão Lopes, 1400/01, CEP: 13087-051

Campinas - SP, Brasil.

E-mail: laurita@rc.unesp.br 
O prognóstico do talento e do desempenho esportivo constitui um tema de especial interesse no âmbito das ciências do esporte. Wolf (1990) define o prognóstico como um esforço para descrever algo que acontecerá no futuro a partir de informações prévias relevantes. O processo de promoção, detecção e seleção de talentos tem sido tema constante de discussões, estudos e publicações na área do esporte (Hebbelink, 1989; Hopkins, 1977; Kiss, Böhme, Mansoldo, \& Regazzini, 2004; Maia, 1996; Marques, 1993; Matsudo, 1996; Peltola, 1992; Williams \& Reilly, 2000), porém ainda não há consenso a respeito da teoria da identificação e desenvolvimento do talento.

Considerando os apontamentos da literatura, evidencia-se que questões associadas à identificação e desenvolvimento de talentos emergem como problemas centrais, suscitando a atenção de inúmeros pesquisadores. Vaeyens et al. (2008) definem a identificação do talento como o processo de reconhecimento de indivíduos com potencial de excelência para um determinado esporte, ao passo que o desenvolvimento do talento implica propiciar o mais apropriado ambiente de aprendizagem para a realização do potencial. Vale destacar que a identificação e o desenvolvimento do talento devem ser entendidos como um processo dinâmico provendo oportunidade para o desenvolvimento de objetivos de longo prazo (Vaeyens et al., 2006) e não somente na perspectiva da performance pontual em testes e medidas. Martindale, Collins e Daubney (2005) destacam algumas das principais premissas no processo de treinamento até o alto rendimento, ressaltando a necessidade da visão de longo prazo, caracterizada pelo entendimento de que o desempenho em determinados momentos do processo, não necessariamente reflete $\mathrm{o}$ potencial de desenvolvimento do indivíduo, por outro lado, faz-se necessário o acompanhamento longitudinal, em uma perspectiva multidimensional, durante o processo de treinamento dos jovens.

A Ginástica Artística (GA) é uma modalidade esportiva que apresenta uma particularidade que deve ser contemplada na reflexão sobre o desenvolvimento do talento. A idade mínima, determinada pela Federação Internacional de Ginástica (FIG), para participação em Jogos Olímpicos (JO), é de 16 anos. Portanto, enquanto para muitas das modalidades esta faixa etária contempla fases de formação, para muitas ginastas, por outro lado, o momento é de alcance dos primeiros resultados superiores ou mesmo dos máximos resultados esportivos.

Essa determinação concernente à idade mínima de participação em competições internacionais surgiu na década de oitenta, com o objetivo de limitar a participação de ginastas muito novas na categoria adulta, decorrente de uma preocupação com a questão da especialização precoce. Um exemplo marcante que retrata bem esse fato foi o da ginasta romena Nádia Comanecci, que teve destaque nos Jogos Olímpicos de Montreal em 1976 no Canadá, quando foi campeã olímpica e a primeira ginasta a obter a nota 10 na história da modalidade em JO, aos 14 anos de idade (Smoleuskiy \& Gaverdouskiy, 1996).

A predominância de ginastas muito jovens é parte do contexto atual da modalidade. Ao longo da história da GA, foi possível observar que há 40 anos, predominavam as mulheres mais velhas, como a ginasta Larisa Latynina, que foi campeã olímpica aos 34 anos de idade. $\mathrm{Na}$ década de 70 , começaram a surgir as "pequenas notáveis" como Olga Korbut e Nadia Comaneci que, no auge de suas carreiras, ainda encontravam-se entre o período da infância e da adolescência (Ferreira Filho, Nunomura, \& Tsukamoto, 2006).

A GA contemporânea, com exigências de realização de muitas dificuldades técnicas (elementos de alta dificuldade e valor) e, ao mesmo tempo, a perfeição da execução dos elementos, requer uma especialização desportiva em baixa faixa etária. Em grande parte, isso se justifica devido ao fato de que a realização de exercícios no regime de facilitação (com o auxílio do técnico, utilização do trampolim acrobático, fosso, tumble track, 
entre outros), em exercícios de maior dificuldade, é favorecida com crianças de menor estatura e massa corporal. Muitos exercícios começam a ser ensinados às jovens ginastas com o emprego desses meios, com o intuito de desenvolver a coordenação e a força especial, quando a ginasta ainda não possui capacidade de executá-los sozinha nos aparelhos oficiais.

O início do direcionamento do treinamento para fins de rendimento desportivo, o que corresponde à etapa de especialização inicial em diferentes desportos, leva em consideração, entre outros parâmetros, a faixa etária em que se atinge a etapa de resultados superiores, bem como o tempo de treinamento que é necessário para se atingir esse nível em uma determinada modalidade. Além disso, também se leva em consideração as características e, principalmente, o desenvolvimento das capacidades motoras determinantes na modalidade desportiva. Na GA, segundo alguns autores, o tempo aproximado de treinamento é de oito anos para que se alcance a etapa de resultados superiores, nesse momento as ginastas têm entre 15 e 19 anos de idade (Smoleuskiy \& Gaverdouskiy, 1996; Zakharov \& Gomes, 2003). Filin e Volkov (1998) mencionam que este período é de cerca de seis anos, mas o consideram a partir da categoria juvenil até a obtenção do nível internacional. A partir disso determinou-se que a categoria competitiva inicial (pré-infantil), em nível nacional na GA, tenha início na faixa etária compreendida entre os 9 e os 10 anos.

Na Ginástica Artística, além da baixa faixa etária inicial na modalidade, existem outras características importantes para a determinação do talento desportivo. Para que se faça um diagnóstico das crianças que possuem talento desportivo para a GA competitiva é necessário ter parâmetros de referência. Filin e Volkov (1998) corroboram essa afirmação, enfatizando que "para realizar uma seleção eficiente no desporto juvenil, é importante conhecer não somente o modelo ideal desportivo, mas também os modelos inter- mediários que caracterizam o atleta nas várias etapas da evolução desportiva".

Internacionalmente, existem pesquisas sobre o perfil de ginastas campeãs que servem de referência nesse processo, contribuindo para que a determinação do talento desportivo seja a mais adequada e objetiva possível, mas são insuficientes "os estudos que definam características modelo dos jovens atletas nas várias etapas da preparação a longo prazo" (Nabatnikova \& Jordin, apud Filin \& Volkov, 1998).

O ambiente e infra-estrutura também devem ser considerados quando se busca entender $o$ processo de formação e o desenvolvimento do talento. Estas questões emergem e são cruciais em várias modalidades esportivas, no entanto, parecem exercer papel fundamental na GA, especialmente em nosso país, considerando $\mathrm{o}$ restrito acesso às instituições de ensino e treinamento da modalidade e o escasso conhecimento da população em geral.

Estes aspectos que podem ser limitantes do desempenho desportivo e do desenvolvimento do talento incluem as condições sociais, como família, escola, amigos, técnicos, apoio financeiro, a valorização da sociedade e as condições materiais disponíveis para a prática como aparelhos, equipamentos, local de treinamento, entre outros.

O conhecimento do ambiente de aprendizagem e treinamento que proporcionou o desenvolvimento de atletas de elite da Ginástica Artística Feminina (GAF) no Brasil pode contribuir consideravelmente para um maior entendimento do processo de formação de longo prazo nessa modalidade. Assim, o objetivo deste estudo foi registar a história de vida desportiva de ginastas que representaram o Brasil em Jogos Olímpicos, conhecendo os caminhos percorridos e buscando compreender porque que estes caminhos fizeram destas atletas, representantes do Brasil em Jogos Olímpicos. Para tanto, utilizou-se o depoimento oral das atletas, a fim de reconstruir os respectivos processos de 
formação. A hipótese era que seria possível identificar grupos distintos de ginastas, decorrente das diferentes condições de preparação entre os diferentes períodos (19802004) e que a partir destes conglomerados fosse possível identificar particularidades do processo.

\section{MÉTODO}

Para o desenvolvimento desta pesquisa qualitativa foi utilizado o método de História Oral (Meihy, 2005; Simson, 1988). O método utilizado baseia-se na possibilidade de receber informações de pessoas que participaram desses importantes períodos da GAF no Brasil, reconstruindo o processo de formação de ginastas (Queiroz, 1988).

Segundo Queiroz (1988), a história oral é um termo amplo que recobre uma quantidade de relatos a respeito de fatos não registrados por outro tipo de documentação ou cuja documentação se quer completar. Colhida por meio de entrevistas de variada forma, é registada a experiência de um só indivíduo ou de diversos indivíduos de uma mesma coletividade. Neste último caso busca-se a convergência de relatos sobre um mesmo acontecimento ou sobre um período do tempo.

Portanto, justifica-se a utilização desse método, principalmente por não haver registos sobre a formação desportiva destas ginastas por meio de documentos ou de outras pesquisas publicadas, além do detalhamento dos porquês dos acontecimentos vividos na carreira desportiva de cada ginasta, que por meio do método de história oral pode ser conseguido.

Portelli (1997) ressalta que o diferencial da utilização deste método é a "subjetividade do expositor" e comenta posteriormente: "fontes orais contam-nos não apenas o que o povo fez, mas o que queria fazer, o que acreditava estar fazendo e o que agora pensa que fez".

Entre as várias técnicas de desenvolvimento do método de História Oral, o "depoimento oral" foi utilizado nesta pesquisa. No depoimento oral, o pesquisador propõe um tema para organizar o relato de vida das pessoas que serão estudadas. A pesquisa está focalizada em um determinado tema, sendo neste estudo a "história de vida esportiva" destas ginastas. "Da 'vida' de seu informante só lhe interessam os acontecimentos que venham se inserir diretamente no trabalho, e a escolha é unicamente efetuada com este critério" (Queiroz, 1988).

Apesar do método de História Oral ser essencialmente qualitativo, permite levantar alguns dados quantitativos, como volume de treino em horas, volume de séries em uma sessão diária, entre outros, que podem ser incorporados na discussão qualitativa de um tema focalizado, como sobre a estrutura do treinamento de uma forma mais ampla, por exemplo. São informações sobre a formação desportiva das ginastas e que podem ser somadas aos dados qualitativos, acrescentando assim dados ao registo histórico. Sobre este assunto, Queiroz (1992) ressalta que as associações das duas abordagens (qualitativa e quantitativa) possibilitam um aprofundamento cada vez maior das facetas do objeto de estudo.

\section{Amostra}

Participaram da pesquisa dez ginastas, apresentadas a seguir em ordem cronológica de participação nos Jogos Olímpicos: Cláudia Magalhães (1980), Tatiana Figueiredo (1984), Luísa Parente (1988 e 1992), Soraya Carvalho (1996), Daniele Hypólito (2000, 2004 e 2008), Camila Comin (2000 e 2004), Ana Paula Rodrigues (2004), Caroline Molinari (2004), Daiane dos Santos (2004 e 2008) e Laís Souza (2004 e 2008). O critério estabelecido para determinar o universo da pesquisa foi: ginastas brasileiras participantes (ou classificadas) para os Jogos Olímpicos, na modalidade de Ginástica Artística Feminina até o ano de 2004.

Esta pesquisa foi previamente aprovada pelo Comitê de Ética em pesquisa da Faculdade de Ciências Médicas da Universidade Estadual de Campinas em 27 de março de 2007, tendo o número de parecer: $136 / 2007$. 


\section{Instrumentos e Procedimentos}

Segundo Queiroz (1988), as entrevistas, no caso de depoimentos orais, são diretamente dirigidas pelo pesquisador. Os colaboradores têm consciência de que a pesquisa não é sobre a sua vida, mas sobre uma parte dela, neste caso, focalizada na vida desportiva da colaboradora.

No caso do depoimento oral, o primeiro momento da entrevista é feito de forma bastante livre, a partir de um tema amplo, que nesta pesquisa foi a história desportiva de cada ginasta. Segundo Simson (2006), como nas pesquisas que conduzimos procuramos reconstruir historicamente processos sócioculturais, não trabalhamos com histórias de vida, mas com testemunhos orais. Com esta abordagem, propomos um tema de referência e solicitamos aos depoentes que narrem suas vidas, tendo como guia o tema proposto. Fazemos perguntas sempre que surge uma dúvida, mas, na primeira fase de coleta de informações, é preciso deixar que o informante fale livremente, apenas reconduzindo o relato para o tema-guia quando os caminhos da memória o arrebatam por longos períodos de tempo, levando-o a subtemas que se distanciam do principal ponto de interesse da pesquisa.

Num segundo momento, o pesquisador levanta temas geradores, direcionando para assuntos relevantes da história desportiva do colaborador, com o propósito de aprofundar mais sobre determinados assuntos e lembrá-lo de fatos que, muitas vezes, o próprio atleta não valoriza como parte de sua história pessoal, ou não se aprofundou o suficiente ao falar livremente, ou seja, assuntos que interessam à pesquisa.

Para este momento da entrevista há um roteiro, elaborado com foco em momentos de destaque no desporto, como Campeonatos Mundiais e Jogos Olímpicos e com um propósito abrangente sobre a formação das colaboradoras, assuntos que a própria literatura destaca e considera relevantes neste processo, como: a participação da família, relação técnico/atleta, aspectos nutricionais e psicológicos, estrutura da preparação desportiva, iniciação e especialização desportiva, etc. Além desses assuntos abordados, outros temas foram levantados na busca de informações para o registro de diferentes períodos da GA no Brasil, como infra-estrutura e organização do treinamento, apoio financeiro, encerramento da carreira desportiva, entre outros aspectos relevantes na formação desportiva destas ginastas.

Após essas fases é apresentada uma ficha cadastral de identificação, com o objetivo de colher os dados pessoais e específicos da ginasta, e que é apresentada somente neste momento para não inibir o colaborador na fase inicial do depoimento. Com o encerramento das três fases de coleta de depoimento, solicitou-se às colaboradoras as fotos relacionadas às suas carreiras desportivas, deixando-as à vontade para, se quisessem, as mostrassem à pesquisadora.

A coleta dos depoimentos e seu armazenamento seguro foi seguida de imediata transcrição das entrevistas, ou seja, tradução da língua falada para a língua escrita. Com a transcrição uma parte do registro se perde, pois 'há um empobrecimento" quando comparado à gravação (Queiroz, 1988).

As transcrições de cada entrevista estão disponibilizadas no Laboratório de História Oral (LAHO) do Centro de Memória da UNICAMP.

\section{Análise dos Dados pelo Método Comparativo}

A análise da pesquisa foi realizada a partir dos dados coletados pela pesquisa de campo nos depoimentos das colaboradoras. Posteriormente, as informações de cada ginasta foram cruzadas para ser possível estabelecer relações entre elas e, a partir disso, confrontá-las, destacando e refletindo sobre as diferenças e, principalmente, as semelhanças da formação desportiva das ginastas.

Primeiramente, os arquivos foram fichados e organizados em algumas categorias apontadas em cada uma das textualizações, 
categorias baseadas no roteiro que orientou a coleta de informações dos depoimentos, bem como outras que emergiram no decorrer do processo.

Cada uma das categorias levantadas foi separada em arquivos diferentes, denominados tópicos de análise, em cada um dos quais constam os relatos e registros das diferentes ginastas sobre um mesmo tema. Cada "recorte" do discurso de cada ginasta foi identificado com o seu nome e a página de sua textualização. A partir disso foi feita a análise e discussão dos dados dos depoimentos, utilizando-se do embasamento proveniente das informações levantadas na literatura estudada, discordando, confirmando, ou mesmo oferecendo colaborações com novas abordagens.

Posteriormente, em cada tópico de análise foi realizado o agrupamento dos depoimentos das ginastas, de acordo com as semelhanças identificadas entre as condições de treinamento de cada uma delas, o que está intimamente relacionado com a época em que se deu o treinamento. Deste modo, emergiram três grupos distintos e em seguida cada tópico de análise foi realizado segundo $\mathrm{o}$ agrupamento apresentado na Tabela 1 .

Tabela 1

Grupos de Ginastas da pesquisa separadas por semelhanças de cada época

\begin{tabular}{cc}
\hline Grupo & Ginastas \\
\hline Ginastas Pioneiras & Cláudia Magalhães \\
& $\begin{array}{c}\text { Tatiana Figueiredo } \\
\text { Luisa Parente }\end{array}$ \\
\hline \multirow{3}{*}{ Ginastas de Transição } & Soraya Carvalho \\
& Daniele Hypólito \\
& Camila Comin \\
& Daiane dos Santos \\
\hline \multirow{2}{*}{ Ginastas da Nova } & Laís Souza \\
Geração & Caroline Molinari \\
& Ana Paula Rodrigues \\
\hline
\end{tabular}

Decorrente das informações provenientes dos depoimentos orais das Ginastas foi possível identificar quatro tópicos específicos de análise: a) estrutura e organização dos treinos das ginastas, b) tempo de duração da etapa preliminar (escolinha), c) volume de treinamento diário nas diferentes etapas, e d) tempo de alcance dos resultados superiores.

\section{RESULTADOS E DISCUSSÃO}

A estrutura e organização dos treinos das ginastas foram se modificando ao longo do tempo, culminando nas gerações de ginastas que puderam usufruir da estrutura de treinamento da seleção brasileira comandada por técnicos ucranianos contratados pela Confederação Brasileira de Ginástica (CBG), entre os anos 1999 e 2008. Relevante destacar que esses técnicos possuíam comprovada experiência na modalidade, tendo inclusive formado campeãs mundiais e olímpicas. No grupo de ginastas pioneiras, o qual não teve a oportunidade de desfrutar dessa estrutura, temos três ginastas que desenvolveram grande parte de seus treinos nas entidades da cidade do Rio de Janeiro, sendo que apenas a "Ginasta 2" começou em São Paulo, mas logo no início a família mudou-se para o Rio de Janeiro, dando continuidade durante aproximadamente cinco anos aos treinamentos na cidade, posteriormente preparou-se para os Jogos Olímpicos por cerca de um ano e meio nos EUA e em seguida retornou ao Rio de Janeiro.

Em relação ao tempo em que permaneceram na etapa de preparação preliminar, chamada popularmente de escolinha, esta geração passou pouco tempo, tendo vivido rapidamente esta etapa.

A "Ginasta 1" lembra-se que ficou menos de um ano na etapa de preparação preliminar, antes de ser direcionada à etapa de especialização inicial, com aumento de carga horária e um direcionamento para competições nas sessões de treinamento. Ela começou na Ginástica Artística entre os 12 e 13 anos de idade e, portanto, não chegou a competir nas categorias de base. A "Ginasta 2" comenta que ficou pouquíssimo tempo, após um teste com as crianças da escolinha, passou para a equipe de treinamento. A "Ginasta 3" lembra-se de ter ficado menos de seis meses na escolinha, 
passando em seguida para a etapa de especialização inicial.

Após a fase de transição da etapa de preparação preliminar (escolinha) para a etapa de especialização inicial, houve um incremento pronunciado no volume de treino para todas as atletas.

A "Ginasta 1" revela que, nesse momento, a duração da sessão de treino chegava a seis horas. A "Ginasta 2", fala que seu treinamento só mudou para duas sessões diárias quando foi treinar nos EUA, sendo até então cinco horas por dia, no Tijuca Tênis Clube/RJ. Posteriormente, quando retornou ao Brasil, voltou a realizar apenas uma sessão e em seguida, já no Clube de Regatas do Flamengo, quando iniciou a preparação para os $\mathrm{JO}$, retomou as duas sessões de treinamento por dia. A "Ginasta 3" fala da progressão mais gradativa de seus treinos durante sua carreira, até chegar a duas sessões de treino por dia a partir dos 15 anos de idade.

Na geração seguinte, nomeada neste estudo como ginastas de transição, as quatro ginastas passaram rapidamente pela etapa de preparação preliminar como a geração das pioneiras. Diferentemente das demais apenas a "Ginasta 6", que ficou nesta fase durante um ano. A "Ginasta 7" não chegou sequer a passar pela escolinha, a "Ginasta 4" não se lembra, mas diz ter sido muito rápido e a "Ginasta 5" diz ter ficado por cerca de três meses.

Com os treinamentos sendo direcionados para a competição, a carga horária também foi modificada e progressivamente aumentada para todas, fato esse relatado também pelas ginastas da geração anterior. Mas a diferença com relação à geração pioneira é que as ginastas de transição iniciaram os treinamentos em duas sessões diárias antes da obtenção de grandes títulos ou classificações para os Jogos Olímpicos. A "Ginasta 3" passou a treinar em dois períodos apenas para os JO de Seul e a "Ginasta 2", na estrutura dos EUA, quando ainda não acontecia no Brasil, mas também visando a classificação para os JO de Los Angeles. A "Ginasta 1", que participou dos
JO em 1980, nunca chegou a treinar duas sessões diárias.

A "Ginasta 4" relata que treinava, em Brasília, próximo de quatro horas nos primeiros anos da carreira desportiva. No Clube de Regatas do Flamengo, a organização do treino já era com duas sessões diárias, de segunda a sábado, com folga na segunda sessão das quartas-feiras e dos sábados. A "Ginasta 6" treinava três horas por sessão, com uma frequência de três vezes por semana inicialmente e aos oito anos chegou a treinar quatro horas todos os dias. Entre os 15 e 16 anos começou a treinar em dois períodos diários. A "Ginasta 7" treinou um período por dia, apenas durante o primeiro ano que chegou ao Grêmio Náutico União passando para dois períodos posteriormente, chegando a cerca de seis horas por dia em Curitiba, onde passou a integrar a seleção brasileira.

A "Ginasta 5" começou em Santo André com treinamento de três horas diárias durante os primeiros quatro anos e depois se mudou para a Academia Yashi, aos 10 anos de idade, quando já referiu a mudança de carga horária dos treinos para dois períodos, carga essa que depois foi mantida no Clube de Regatas do Flamengo, chegando a sete horas diárias.

As três ginastas da nova geração apresentam mais semelhanças nesse aspecto, pois foram mais cedo integradas ao treinamento no Centro de Excelência da Confederação Brasileira de Ginástica (CBG) onde a seleção brasileira se concentrou oficialmente até 2008, principalmente as "Ginastas 9 e 10" que são naturais de Curitiba.

Sobre o tempo que essas ginastas permaneceram na etapa de preparação preliminar, na qual ainda pode acontecer uma variedade de práticas desportivas, utilização de método de jogo e de competição para motivação das crianças nas aulas, ainda de forma mais lúdica (Smoleuskiy \& Gaverdouskiy, 1996), as "Ginastas 8 e 9" ficaram aproximadamente seis meses. A "Ginasta 10", que iniciou a modalidade aos cinco anos, diz ter ficado próximo de três anos nesta etapa, mas 
analisando seu depoimento é possível notar que ela considerou escolinha como todo o período que treinou na praça Oswaldo Cruz e não apenas o período sem direcionamento competitivo na modalidade, que já teve início neste mesmo local.

Em relação ao aumento no volume do treinamento em horas, a progressão aconteceu da seguinte forma: a "Ginasta 8" começou seus treinamentos em duas sessões de treino diárias por volta dos 10 anos de idade, "Ginasta 9" aos 13 anos e a "Ginasta 10" aos 11 anos aproximadamente. Esse fato sugere o início da etapa de especialização aprofundada, quando há um aumento substancial no volume de treinamento dos atletas (Zakharov \& Gomes, 2003) e corresponde à faixa etária sugerida por Smoleuskiy e Gaverdouskiy (1996), pautada nos estudos descritivos da carreira de grandes campeões da modalidade, principalmente da extinta União Soviética.
Além disso, é possível diagnosticar, a partir dos depoimentos, que as ginastas treinavam no Centro de Excelência cerca de seis horas e meia, divididas em duas sessões de treino diárias, o que se assemelha ao volume de treino das ginastas russas, cujo volume é de cinco a seis horas. Contudo, esse volume, pode dividir-se em até três sessões diárias (Arkaev \& Suchilin, 2004), o que poderia ser considerado mais racional, pois possibilitaria mais períodos de recuperação entre as sessões de treino mais curtas, o que promoveria maior qualidade de execução técnica, característica esta altamente específica da GA.

De todo modo, é razoável admitir que o incremento do volume de treinamento das ginastas do grupo denominado de "transição" e, notadamente do grupo da "nova geração" representou um avanço significativo no processo de preparação visando o alto rendimento.

Tabela 2

Relação das etapas de preparação de muitos anos e as diferentes gerações em JO (1980-2004)

\begin{tabular}{|c|c|c|c|}
\hline Etapa/Grupos & Ginastas Pioneiras & Ginastas de Transição & Ginastas da Nova Geração \\
\hline $\begin{array}{l}\text { Preparação } \\
\text { preliminar }\end{array}$ & $\begin{array}{l}\text { Ginasta 1: um ano } \\
\text { Ginasta 2: pouco, logo já } \\
\text { fez teste para a } \\
\text { especialização inicial } \\
\text { Ginasta 3: menos de } 6 \\
\text { meses, idem Ginasta } 2\end{array}$ & $\begin{array}{l}\text { Ginasta 4: não se lembra, } \\
\text { mas pouco tempo } \\
\text { Ginasta 5: } 3 \text { meses } \\
\text { Ginasta 6: um ano } \\
\text { Ginasta 7: não participou } \\
\text { desta etapa }\end{array}$ & $\begin{array}{l}\text { Ginasta } 9 \text { e 8: aproximada- } \\
\text { mente } 6 \text { meses } \\
\text { Ginasta 10: três anos }\end{array}$ \\
\hline $\begin{array}{l}\text { Especialização } \\
\text { inicial }\end{array}$ & $\begin{array}{l}\text { Ginasta 1: } 6 \text { horas diárias } \\
\text { Ginasta 2: } 5 \text { horas por dia } \\
\text { Ginasta 3: 2-3 horas por dia } \\
\text { e aumento gradativo de } \\
\text { horas. }\end{array}$ & $\begin{array}{l}\text { Ginasta 4: } 4 \text { horas diárias } \\
\text { Ginasta } 5 \text { e } 6: 3 \text { horas } \\
\text { diárias (Ginasta 6, no } \\
\text { primeiro ano } 3 \text { vezes por } \\
\text { semana) } \\
\text { Ginasta 7: primeiro ano } \\
\text { uma sessão e depois duas } \\
\text { sessões diárias (total de } 6 \\
\text { horas) }\end{array}$ & $\begin{array}{l}\text { Ginasta 9: } 3 \text { horas diárias } \\
\text { Ginasta 8: } 4 \text { horas diárias } \\
\text { Ginasta 10: } 3-5 \text { horas } \\
\text { diárias }\end{array}$ \\
\hline $\begin{array}{l}\text { Especialização } \\
\text { aprofundada }\end{array}$ & $\begin{array}{l}\text { Ginasta 1: } 6 \text { horas diárias } \\
\text { Ginastas } 2 \text { e } 3 \text { : duas sessões } \\
\text { diárias }\end{array}$ & $\begin{array}{l}\text { Ginasta } 4,5 \text { e } 7 \text { : duas } \\
\text { sessões diárias } \\
\text { Ginasta 6: } 4 \text { h30min diárias } \\
\text { e aos } 15 \text { anos duas } \\
\text { sessões diárias }\end{array}$ & $\begin{array}{l}\text { Ginasta 9: duas sessões } \\
\text { diárias } \\
\text { Ginasta 8: duas sessões } \\
\text { diárias } \\
\text { Ginasta 10: duas sessões } \\
\text { diárias }\end{array}$ \\
\hline $\begin{array}{l}\text { Resultados } \\
\text { Superiores }\end{array}$ & $\begin{array}{l}\text { Ginasta 1: } 6 \text { horas diárias } \\
\text { (uma sessão) } \\
\text { Ginastas } 2 \text { e } 3 \text { : duas sessões } \\
\text { diárias }\end{array}$ & Todas duas sessões diárias & Todas duas sessões diárias \\
\hline
\end{tabular}


Adicionalmente, o incremento da quantidade de prática e particularmente da qualidade do treinamento, que parece estar associada à estrutura de treinamento da seleção brasileira com os técnicos ucranianos, emerge como um fator crítico para o sucesso destas ginastas no âmbito internacional. Ericsson (1996) afirma que o nível de desempenho é determinado pela quantidade de tempo despendido realizando uma tarefa bem definida com um nível de dificuldade adequado ao indivíduo, com feedback informativo, e oportunidade para repetições e correções de erros.

Este ambiente criado pela permanência em um centro de excelência com profissionais notadamente reconhecidos pela competência na formação e treinamento de atletas de alto rendimento, parece ter tido um papel central no "salto de qualidade" da ginástica artística feminina brasileira, para as gerações "de transição" e "nova geração".

Em relação ao tempo de preparação para os Jogos Olímpicos, é possível verificar por meio dos depoimentos que para a "Ginasta 3" acontece aos 15 anos, 9 anos após a iniciação na GA, para a "Ginasta 2" aos 16 anos, oito anos após seu início e para a "Ginasta 1", cinco a seis anos após o início na modalidade, aos 18 anos, quando atingem a etapa de resultados superiores.

Em relação às ginastas de transição, todas tiveram cerca de 10 anos de treinamentos até o primeiro JO de cada uma, sendo a "Ginasta 4" com 12 anos de preparação até os JO de 1996 aos 18 anos de idade, a "Ginasta 5" e a "Ginasta 6" com 11 anos de treinamento para os JO de 2000, e 16 e 17 anos de idade respectivamente, e a "Ginasta 7" com nove anos de preparação até os JO de 2004 e 21 anos de idade.

Porém, antes de atingirem a etapa de resultados superiores nos $\mathrm{JO}$, as ginastas tiveram seus primeiros resultados expressivos com tempos bem diferentes de treinamento. As ginastas pioneiras têm seus primeiros resultados expressivos cerca de quatro a cinco anos após o início na modalidade. Na geração de ginastas de transição, a "Ginasta 4" próximo de quatro anos de treinamento foi campeã brasileira já na categoria pré-infantil aos 10 anos de idade, o que pode ser considerado como finalização da etapa de especialização inicial e início da etapa de especialização aprofundada. A "Ginasta 5" teve seus primeiros resultados expressivos aproximadamente após seis anos de treinamento, sendo campeã brasileira na categoria adulta, quando ainda era infantil. Pela exigência dos próprios exercícios para esse tipo de resultado, demonstrou estar, naquele momento, aos 12 anos, na etapa de especialização aprofundada. Diferentemente da maioria das atletas que se especializam na GA, a "Ginasta 7" iniciou mais tardiamente, porém, apesar disso, teve uma evolução muito rápida na modalidade e começou a despontar nas competições dois anos após seu início, em 1997, aos 14 anos, quando foi convocada pela primeira vez para compor a seleção brasileira em um campeonato sul-americano. Os dados da "Ginasta 7", nesse aspecto, diferem substancialmente do que está descrito na literatura que trata do processo de formação a longo prazo das ginastas (Arkaev \& Suchilin, 2004; Smoleuskiy \& Gaverdouskiy, 1996).

A "Ginasta 6" começa a ter resultados significativos aproximadamente quatro anos após o seu início na modalidade. O fato que comprova este destaque é a primeira convocação para integrar a seleção brasileira de GA entre 10 e 11 anos de idade, que segundo Smoleuskiy e Gaverdouskiy (1996) representa a passagem da etapa de especialização inicial para a etapa de especialização aprofundada.

As ginastas da nova geração assemelham-se às das gerações anteriores, pois o tempo de preparação para os JO oscila entre 11 e 13 anos de treinamento, sendo a "Ginasta 9" com 13 anos desde o início na modalidade, a "Ginasta 8" com 12 anos e a "Ginasta 10" com 11 anos, todas para os JO de 2004. Em relação à etapa de resultados superiores, a Olimpíada pode ser considerada um marco, porém a participação no Campeonato Mundial Pré-olímpico de 
2003, demonstra que as ginastas já se encontravam nessa etapa. A idade das ginastas na participação dos JO de Atenas foi: "Ginasta 9" aos 18 anos, "Ginastas 8 e 10" aos 16 anos, sendo que a "Ginasta 8" ainda participou em 2008 dos JO de Pequim aos 20 anos, competindo em alguns aparelhos para contribuir para a classificação da equipe brasileira.

A Tabela 3 apresenta a idade de todas as ginastas brasileiras participantes de JO desde 1980 até 2004, para melhor visualização e comparação, a qual mostra uma semelhança na faixa etária na primeira participação em JO entre 15 e 18 anos, fato que é corroborado pelos dados da literatura que apresentam as "zonas de possibilidades ótimas", zona essa que corresponde à etapa de resultados superiores, de ginastas entre 15 e 19 anos (Smoleuskiy \& Gaverdouskiy, 1996).

Em relação aos anos de treinamento até a participação em $\mathrm{CM}$ e JO, as brasileiras também estão na faixa correspondente ao que é relatado pela literatura, que fica em torno de 10 anos de treinamento (Smoleuskiy \& Gaverdouskiy, 1996). Com exceção da "Ginasta 1", é maior a semelhança entre as ginastas brasileiras a partir da geração de transição.

Investigações prévias acerca do desenvolvimento de atletas de elite têm sustentado o papel fundamental dos anos de treinamento e prática para se alcançar o alto rendimento e a expertise para uma determinada atividade. Ademais, também não é recente, certo consenso sobre as "leis gerais" que determinam o desenvolvimento, entre elas a "regra dos 10 anos" (Simon \& Chase, 1973). Este modelo parece ser corroborado pelos achados do presente estudo.

A "regra dos 10 anos" também foi corroborada em estudos com experts em música (Ericsson, Krampe, \& Tesch-Römer, 1993), natação (Kalinowski, 1985) e tênis (Monsaas, 1985). No tocante à Ginástica Artística, particular-mente no que diz respeito às atletas de alto rendimento do Brasil, o presente estudo parece ser o primeiro a indicar a pertinência de um modelo centrado na "regra dos 10 anos".

Smoleuskiy e Gaverdouskiy (1996) afirmam que na GA a etapa de preparação preliminar caracteriza-se mais frequentemente pela faixa etária de cinco a oito anos para meninas. No

Tabela 3

Idade das ginastas em cada participação em JO e respetivo tempo de treinamento (TT)

\begin{tabular}{|c|c|c|c|c|c|c|}
\hline Ginastas & $\begin{array}{c}\text { Idade } \\
\text { nos JO }\end{array}$ & $\begin{array}{l}\text { TT até os JO } \\
\text { (1 }{ }^{\mathrm{a}} \text { participação) }\end{array}$ & $\begin{array}{l}\text { Idade nos JO } \\
\text { (2a participação) }\end{array}$ & $\begin{array}{c}\text { TT até os JO } \\
\text { (2a participação) }\end{array}$ & $\begin{array}{c}\text { Idade nos JO } \\
\text { (3a participação) }\end{array}$ & $\begin{array}{c}\text { TT até os JO } \\
\text { ( } 3^{\mathrm{a}} \text { participação) }\end{array}$ \\
\hline Ginasta 1 & 18 anos & 5 anos & & & & \\
\hline Ginasta 2 & 16 anos & 9 anos & & & & \\
\hline Ginasta 3 & 15 anos * & 9 anos & 19 anos & 13 anos & & \\
\hline Ginasta 4 & 18 anos & 12 anos & & & & \\
\hline Ginasta 5 & 16 anos & 11 anos & 20 anos & 15 anos & 24 anos & 19 anos \\
\hline Ginasta 6 & 17 anos & 11 anos & 21 anos & 15 anos & & \\
\hline Ginasta 7 & 21 anos & 9 anos & 25 anos & 13 anos & & \\
\hline Ginasta 8 & 16 anos & 12 anos & 20 anos & 16 anos & & \\
\hline Ginasta 9 & 18 anos & 13 anos & & & & \\
\hline Ginasta 10 & 16 anos & 11 anos & & & & \\
\hline
\end{tabular}

Nota: TT $=$ Tempo de treinamento

Fonte: Schiavon (2009, p. 228); *Até 1988 era permitida a participação de ginastas com 15 anos de idade (ano que completa) 
caso das ginastas brasileiras pesquisadas, é possível verificar que oito das dez ginastas passaram pela etapa de preparação preliminar na faixa etária indicada pela literatura específica (Smoleuskiy \& Gaverdouskiy, 1996). As exceções são, "Ginastas 1 e 7", que iniciaram a modalidade tardiamente. A "Ginasta 7" afirma não ter passado por essa etapa, direcionando-se diretamente para a etapa de especialização inicial.

Outra possibilidade de análise se faz em relação ao quadro de ginastas que participou de mais de um JO, sendo $50 \%$, pois cinco das dez ginastas tiveram mais de uma oportunidade de competir em JO como representantes brasileiras ("Ginasta 5" participou em três). Esse fato pode ser analisado de duas formas: como uma preparação a longo prazo, na qual as ginastas têm a possibilidade de permanecer na etapa de resultados superiores por mais tempo, ou ao mesmo tempo pode remeter à falta de renovação de ginastas no país, que faz com que ginastas já na etapa de manutenção de resultados permaneçam entre as melhores ginastas do país.

Mesmo com algumas ginastas sendo exceções nas comparações entre as dez representantes brasileiras do período entre 1980 e 2004, é possível constatar muitas semelhanças nas trajetórias destas dez ginastas brasileiras participantes de JO, o que pode apontar para alguns parâmetros e espelhos para outros técnicos da modalidade na formação de ginastas olímpicas.

\section{CONSIDERAÇÕES FINAIS}

$\mathrm{O}$ presente artigo apresentou informações sobre a formação desportiva de ginastas brasileiras de alto rendimento desportivo, mais especificamente sobre estrutura e organização dos treinos das ginastas, tempo de duração da etapa de preparação preliminar, volume de treinamento diário nas diferentes etapas e tempo de alcance dos resultados superiores. O depoimento oral das atletas brasileiras participantes em Jogos Olímpicos teve como objetivo central reconstruir os respectivos processos de formação.

A hipótese de que seria possível identificar grupos distintos de ginastas, decorrente das diferentes condições de preparação entre os diferentes períodos (1980-2004) foi parcialmente corroborada.

Observou-se que a estrutura e organização dos treinos das ginastas foram se modificando ao longo do tempo, culminando com uma condição particular entre os anos 1999 e 2008. Independente da "geração", os resultados revelam que as atletas permaneceram pouco tempo na etapa de preparação preliminar. Quanto à carga horária, as ginastas de transição iniciaram os treinamentos em duas sessões diárias antes da obtenção de grandes títulos ou classificações para os Jogos Olímpicos, se diferenciando das gerações anteriores. Os volumes de treinamento, adicionado a qualidade do processo, associadas, por sua vez à estrutura, parecem ser variáveis críticas para o sucesso das ginastas "de transição" no cenário internacional.

Os resultados da presente investigação, identificando variáveis críticas que diferenciaram as ginastas ao longo do tempo e, possivelmente, influenciaram os resultados internacionais obtidos, poderiam ser utilizados como parâmetros e espelhos por outros técnicos da modalidade na formação de ginastas olímpicas, contribuindo para a organização teórica e metodológica do treinamento de longo prazo.

\section{REFERÊNCIAS}

Arkaev, L. I., \& Suchilin, N. G. (2004). Gymnastics: How to create champions. Oxford: Meyer \& Meyer Sport.

Ericsson, K. A. (1996). The road to excellence: The acquisition of expert performance in the arts and sciences, sports and games. Hilsdale, NJ: Lawrence Erlbaum.

Ericsson, K. A., Krampe, R., \& Tesch-Römer, C. (1993). The role of deliberate practice in the acquisition of expert performance. Psychological Review, 100, 363-406. 
Ferreira Filho, R. A., Nunomura, M., \& Tsukamoto, M. H. (2006). Ginástica artística e estatura: Mitos e verdades na sociedade brasileira. Revista Mackenzie de Educação Física e Esporte, 5(2), 21-31.

Filin, V. P., \& Volkov, V. M. (1998). Seleção de talentos nos desportos. Londrina-PR: Midiograf.

Hebbelinck, M. (1989). Identificação e desenvolvimento de talentos no esporte: Relatos cineantropométricos. Revista Brasileira de Ciência e Movimento, 4, 46-62.

Hopkins, D. R. (1977). Factor analysis of selected basketball skills tests. Research Quarterly for Exercise and Sport, 48(3), 535-540.

Kalinowski, A. G. (1985). The development of olympic swimmers. In B. S. Bloom (Ed.), Developing talent in young people (pp. 139-192). New York: Ballantine.

Kiss, M. A., Böhme, M. T., Mansoldo A. C., \& Regazzini, M. (2004). Desempenho e talentos esportivos. Revista Paulista de Educação Física, 18, 89-100.

Maia, J. A. (1996). O prognóstico do desempenho do talento esportivo: Uma análise crítica. Revista Paulista de Educação Física, 10(2), 179193.

Marques, A. T. (1993). Bases para a estruturação de um modelo de detecção e seleção de talentos desportivos em Portugal. Espaço, 1 (1), 47-58.

Martindale, R. J. J., Collins, D., \& Daubney, J. (2005). Talent development: A guide for practice and research within sport. Quest, 57(4), 353-375.

Matsudo, V. K. R. (1996). Prediction of future athletic excellence. In O. Bar-Or (Ed.), The child and adolescent athlete (pp. 92-109). Oxford: Blackwell Science.

Meihy, J. C. (2005). Manual de história oral (5 $5^{\mathrm{a}}$ ed.). São Paulo: Edições Loyola.

Monsaas, J. A. (1985). Learning to be a world-class tennis players. In B. S. Bloom (Ed.), Developing talent in young people (pp. 211-269). New York: Ballantine.

Peltola, E. (1992). Talent identification. New Studies in Athletics, 7, 7-12.
Portelli, A (1997). O que faz a história oral diferente. Revista Projeto História, 14, 25-39.

Queiroz, M. I. (1988). Relatos orais: Do indivizível"ao "divizível”. In O. Von Simson (Ed.), Experimentos com histórias de vida (ItáliaBrasil) (pp. 14-43). São Paulo: Vértice.

Queiroz, M. I. (1992). O pesquisador, o problema da pesquisa, a escolha de técnicas: Algumas reflexões. In A. Lang (Ed.), Reflexões sobre a pesquisa sociológica (pp. 13-29). São Paulo: Centro de Estudos Rurais e Urbanos.

Schiavon, L. M. (2009). Ginástica artística feminina e história oral: A formação desportiva de atletas brasileiras participantes de Jogos Olímpicos (19802004). Tese de Doutorado, Universidade Estadual de Campinas, Campinas, SP, Brasil.

Simon, H. A., \& Chase, W. G. (1973). Skill in chess. American Scientist, 61, 394-403.

Simson, O. R. M. (2006). A arte de recriar o passado: A metodologia da história oral e suas contribuições à promoção do envelhecimento bem sucedido. In A. Neri (Ed.), Desenvolvimento e envelhecimento: Perspectivas biológicas, psicológicas e sociológicas (pp. 141-160). Campinas: Papirus.

Simson, O. R. M. (Ed.) (1988). Experimentos com histórias de vida (Itália-Brasil). São Paulo: Vértice.

Smoleuskiy, V., \& Gaverdouskiy, I. (1996). Tratado general de gimnasia artística deportiva. Barcelona: Paidotribo.

Vaeyens R., Malina, R. M., Janssens, M., Van Renterghem, B., Bourgois, J., Vrijens, J., \& Philippaerts, R. M. (2006). A multidisciplinary selection model for youth soccer: The Ghent Youth Soccer Project. British Journal of Sports Medicine, 40(11), 928-934.

Williams, A. M., \& Reilly, T. (2000). Talent identification and development in soccer. Journal of Sports Science, 18(9), 657-667.

Wolf, R. M. (1990). Prediction in research. In J. P. Keeves (Ed.), Educational research, methodology and measurement: An international handbook (pp. 566- 569). Oxford: Pergamon Press.

Zakharov, A., \& Gomes, A. C. (2003). Ciência do treinamento desportivo ( $\mathrm{a}^{\mathrm{a}}$ ed.). Rio de Janeiro: Grupo Palestra Sport.

(c) EY-No Todo o conteúdo da revista Motricidade está licenciado sob a Creative Commons, excepto quando especificado em contrário e nos conteúdos retirados de outras fontes bibliográficas. 